\title{
The subunits of the S-phase checkpoint complex Mrc1/Tof1/Csm3: dynamics and interdependence
}

\author{
Sonya Dimitrova Uzunova ${ }^{\dagger}$, Alexander Stefanov Zarkov ${ }^{\dagger}$, Anna Marianova Ivanova, Stoyno Stefanov Stoynov \\ and Marina Nedelcheva Nedelcheva-Veleva*
}

\begin{abstract}
Background: The S-phase checkpoint aims to prevent cells from generation of extensive single-stranded DNA that predisposes to genome instability. The S. cerevisiae complex Tof1/Csm3/Mrc1 acts to restrain the replicative MCM helicase when DNA synthesis is prohibited. Keeping the replication machinery intact allows restart of the replication fork when the block is relieved. Although the subunits of the Tof1/Csm3/Mrc1 complex are well studied, the impact of every single subunit on the triple complex formation and function needs to be established.

Findings: This work studies the cellular localization and the chromatin binding of GFP-tagged subunits when the complex is intact and when a subunit is missing. We demonstrate that the complex is formed in cell nucleus, not the cytoplasm, as Tof1, Csm3 and Mrc1 enter the nucleus independently from one another. Via in situ chromatin binding assay we show that a Tof1-Csm3 dimer formation and chromatin binding is required to ensure the attachment of Mrc1 to chromatin. Our study indicates that the translocation into the nucleus is not the process to regulate the timing of chromatin association of Mrc1. We also studied the nuclear behavior of Mrc1 subunit in the process of adaptation to the presence hydroxyurea. Our results indicate that after prolonged HU incubation, cells bypass the S-phase checkpoint and proceed throughout the cell cycle. This process is accompanied by Mrc1 chromatin detachment and Rad53 dephosphorylation.
\end{abstract}

Conclusions: In S. cerevisiae the subunits of the S-phase checkpoint complex Mrc1/Tof1/Csm3 independently enter the cell nucleus, where a Tof1-Csm3 dimer is formed to ensure the chromatin binding of Mrc1 and favor DNA replication and S-phase checkpoint fork arrest. In the process of adaptation to the presence of hydroxyurea Mrcl is detached from chromatin and Rad53 checkpoint activity is diminished in order to allow S-phase checkpoint escape and completion of the cell cycle.

Keywords: Cell cycle, Protein localization, Adaptation, In situ chromatin binding assay, Mrc1, Tof1, Csm3

\section{Background}

The activation of the S-phase checkpoint aims to preserve genome stability when an impediment for strict DNA synthesis arises. It turns on a cascade of events and results in replicational block that provides time for the repair systems to eliminate the problem. Then the ordinary dynamics of the cell cycle is restored and DNA synthesis and segregation completed. A complex of three proteins, named in S. cerevisiae Tof1/Csm3/Mrc1, plays a critical role in that process. Those proteins are conserved among organisms. Tof1's familiar orthologs are

\footnotetext{
* Correspondence: marina@bio21.bas.bg

${ }^{\dagger}$ Equal contributors

Institute of Molecular Biology "Roumen Tsanev", Bulgarian Academy of Sciences, 21 "Acad. George Bonchev" Str., 1113 Sofia, Bulgaria
}

Swi1 in S. pombe and Timeless (Tim1) in human. Csm3's orthologs are Swi3 for fusion yeast and Tipin for H. sapiens and Mrc1's are respectively Mrc1 in S. pombe and Claspin in higher eukaryotes [1-5]. Today they are categorized as S-phase checkpoint mediators [2]. Mediators act as protein bridges (platforms) that bring together sensor or effector kinases, functioning afterwards in the signal cascades. The three proteins are found to co-localize at normal and stalled replication forks $[5,6]$. They co-precipitate together in dynamic and stalled replication forks [7], suggesting that the three proteins form a complex. Tof1, Csm1 and Mrc1 also co-precipitate with subunits of the MCM replicative helicase both from exponentially growing culture and arrested by hydroxyurea (HU) one [7-9]. The synthetic lethality between 
deletions of tof1, csm3 or $m r c 1$ and mutations in polymerase $\alpha$ /primase complex, shows that the products of these genes are interdependent in order to guarantee the correctness of the replication process [7]. These dependencies suggest that the Tof1/Csm3/Mrc1 complex aims to keep together the polymerase and helicase in order to prevent lethality of cells, when DNA synthesis is compromised.

It was shown that lack of Mrc1 leads to MCM-Cdc45 and Pol $\varepsilon$ separation [9-11]. A function to stabilize the forks for Mrc1 and its orthologs was suggested [11,12]. Another S. cerevisiae protein - Ctf4 (Mcl1 in S. pombe and And 1 in $X$. laevis and $H$. sapiens) [13-17] was also found to be involved in cell cycle progression and sister chromatide cohesion $[18,19]$. It physically interacts with GINS and Pol $\alpha$ at replication progressing complex (RPC) [20-25]. Recent data demonstrate that the ortholog of Ctf4 - And1 from Xenopus egg extract binds Tipin, and their binding is necessary for the stable Pol $\alpha$ association to chromatin under unchallenged conditions [26]. Indirect binding to Mrc1 was also revealed [27] and was demonstrated that this binding is sufficient for E3 ubiquitine ligase $\mathrm{SCF}^{\mathrm{Dia} 2}$ association to the replication complex.

Another important actor to regulate replication fork progression is the F-box protein Dia2. It is known that Dia2 interacts with many replication proteins, such as MCMs and GINS [13,27]. Recently, its function was associated with its ability to form a complex with the modular ubiquitin ligase SCF (Skp1/cullin/F box) [28]. A physical interaction between Dia2 and Mrc1 and Ctf4 was demonstrated and was shown that $\mathrm{SCF}^{\text {Dia2 }}$ destabilizes Mrc1 and Ctf4 in a proteasome-dependent manner [29].

Other key actors in the process of S-phase checkpoint activation are the sensor kinase Mec1 (in a complex with Ddc2) and the effector kinase $\operatorname{Rad} 53$ [30-32]. Mrc1 is a substrate for Mec1 and is known to directly interact with Rad53 [33]. At first, in Rad53 independent manner, Mrc1 is Mec1 phosphorylated [34]. Thus, Mrc1 becomes competent to bind Rad53 and predisposes it to Mec1 phosphorylation [35]. The activated Rad53 additionally phosphorylates Mrc1. Although its fundamental function is to bring together Rad53 and Mec1 kinases in order to turn the S-phase checkpoint and to stabilize the replication forks [35-37], mrc1 deletion mutation is not lethal. When knocked out, its function seems to be taken by the specific checkpoint mediator Rad9 [38]. Nevertheless, stalled forks restart much harder in mrc1 $\Delta$ cells when $\mathrm{HU}$ is removed from the media, suggesting a role for Mrc1 to promote stable fork-pausing complex formation and to guarantee recovery after fork arrest [39]. Tourriere and co-workers also demonstrate that in mrc1 $\Delta$ cells, as well as in tof $1 \Delta$ mutants, the S-phase seems to be about
20 min longer, compared to the wild type (WT) yeast cells, most probably as a result of the approximately $40 \%$ slower progression of the replication fork. Claspin depletion also affects fork progression rates in human cell lines [40]. Although the rate of fork progression seems to be reduced in tof $1 \Delta$ as well, it is less pronounced than that in $m r c 1 \Delta$. The absence of Tof1 seems to reflect much stronger on the pausing of the replication forks at the rDNA replication fork barrier (RFB), protein-DNA barriers sites at the tRNA promoters and centromeres [39,41]. In contrast, in tof $1 \Delta$ and in $m r c 1 \Delta$ yeast cells, fork stalling is significantly increased at inverted repeat (IR) provoked hairpins than in WT cells [42]. The authors suggest that both Tof1 and Mrc1 counteract replication fork stalling at such DNA secondary structures.

All the above data indicate the key role of the Tof1/ Csm3/Mrc1 complex for normal replication fork movement and the establishment and regulation of the S-phase checkpoint. Our study examines the importance of every protein of Tof1/Csm3/Mrc1 complex for the nuclear localization and consequent chromatin binding of the other two. The specific role of Mrc1 in the process of adaptation to reduced nucleotide levels is also studied.

\section{Results}

\section{Independent nuclear localization of the subunits of the} Tof1/Csm3/Mrc1 complex

As our study aims to examine the interdependences of the S. cerevisiae S-phase checkpoint proteins Tof1, Csm3 and Mrc1 with regard to their nuclear localization, we first carried out sequence analysis of those proteins for predictive Nuclear Localization Signals (NLS). The NLS is a sequence on the surface of a protein that is used to target the protein to enter the cell nucleus. We used the 'PredictNLS' software [43] that is located at https://rostlab. org/owiki/index.php/PredictNLS. The analysis of the three examined proteins revealed that only Tof1 possesses hypothetical NLS (KKDKRKRRK), starting at the 1013th amino acid. According to the program, this NLS is common for 28 proteins from various organisms, all of them located in nucleus. This prediction data suggest that Tof1 might be the leading protein to target the complex into the nucleus.

As Tof1 is the only one of the three that possesses canonical NLS, we checked whether it is the protein that is responsible for the nuclear localization of Csm3 and consequently Mrc1 in S. cerevisiae. To do that, we used GFP-tagged proteins [Invitrogen ${ }^{\mathrm{Tm}}$; [44]], shortly named TOF1-GFP, CSM3-GFP and MRC1-GFP (See Methods).

To make sure that the three S-phase checkpoint GFPtagged proteins are fully functional, we compared their viability with that of the untagged versions. When grown on a rich YPD media, all three GFP-tagged strands 
revealed viability comparable to the wild-type control (Figure 1A). The GFP-tagged strands also revealed ability to withstand chronic exposure to two different concentrations of the S-phase checkpoint inducing agent $\mathrm{HU}$, similar to that of the wild-type cells (Figure 1A). Then, assuming that the three GFP-tagged strains function as their untagged versions, we used them to delete a gene coding a partner subunit of the S-phase checkpoint complex Tof1/Csm3/Mrc1 that is not GFP-tagged (See Table 1, Methods). As a result, a full set of deletion mutants of the complex's subunits was achieved. We will refer to those strains as: TOF1-GFP; $\operatorname{csm} 3 \triangle$, TOF1-GFP; $\operatorname{mrc1\Delta }$, CSM3-

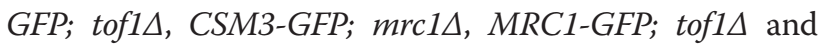
$M R C 1-G F P ; \operatorname{csm} 3 \Delta$. Asynchronous, exponentially growing cells from the constructed strains, as well as the initial GFP strains without deletions, were paraformaldehyde fixed and subjected to fluorescent microscopy analysis to detect the position of GFP-tagged proteins in the cell.
DAPI DNA staining was used for all of the probes to visualize the position of nucleus. Data were documented and analyzed for all of the examined strains (Figure 1B, C, D). As was expected, the control TOF1-GFP, CSM3-GFP and MRC1-GFP strains revealed co-localization of DAPI and GFP signals, indicative of nuclear localization of the respective subunit. Interestingly, all other strains - TOF1GFP; csm3A, TOF1-GFP; mrc1A, CSM3-GFP; tof1 $\triangle$, CSM3-GFP; mrc1A, MRC1-GFP; tof1 $1 \triangle$ and MRC1-GFP; $\operatorname{csm} 3 \Delta$, also revealed co-localization of their GFP and DAPI signals (Figure 1), suggestive of nuclear localization of the three subunits, regardless of the lack of their partners. Additionally, neither of the studied strains with deletions revealed cytoplasmic accumulation of a GFP-tagged protein. These results demonstrate that in $S$. cerevisiae the three subunits of the Tof1/Csm3/Mrc1 S-phase checkpoint complex are independent with regard to their nuclear translocation.

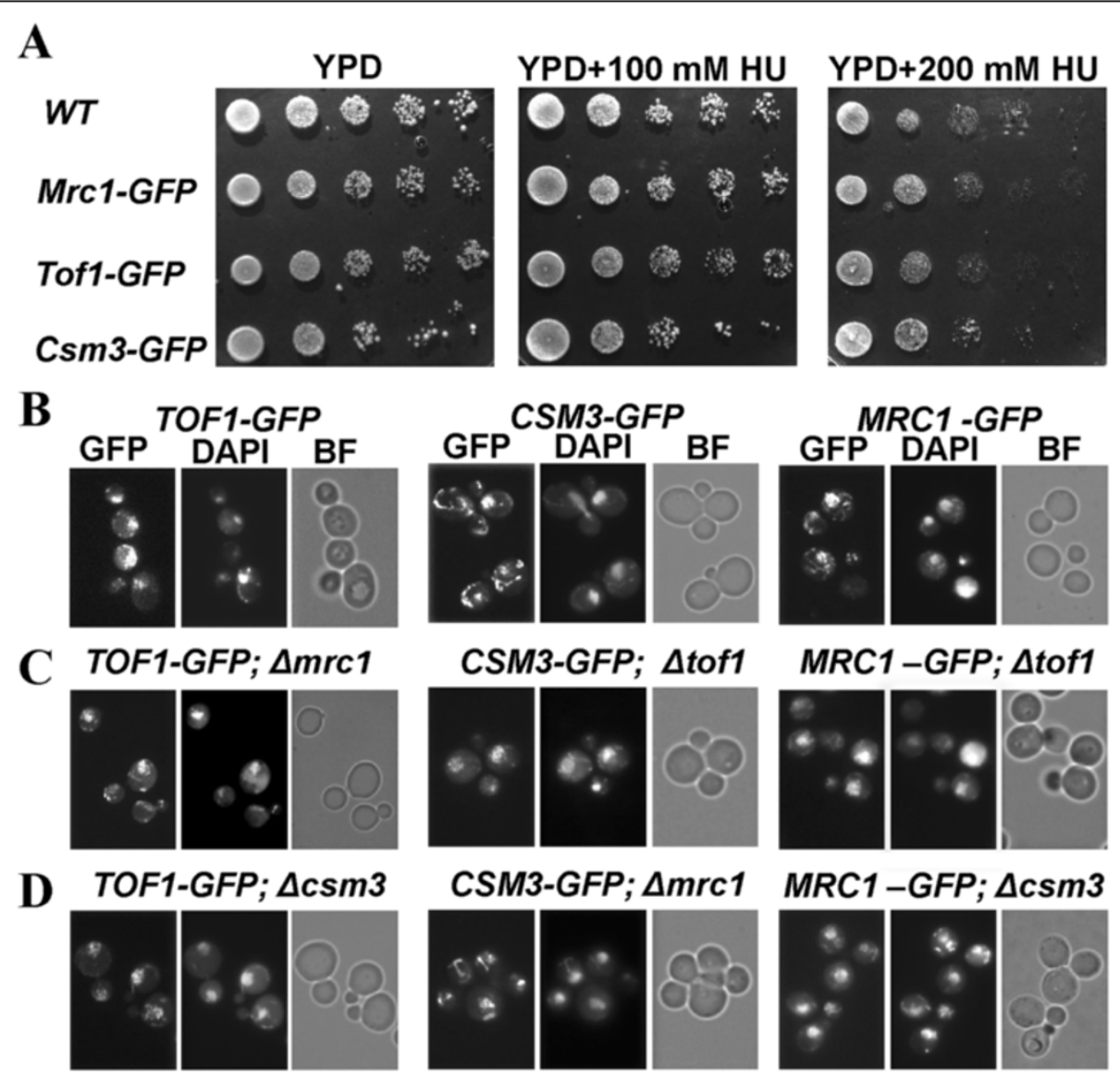

Figure 1 Independent nuclear localization of the subunits of the Tof1/Csm3/Mrc1 complex. (A) Viability test of the S-phase checkpoint GFP-tagged proteins by 10-fold serial dilution assay. $5 \mu \mathrm{L}$ of each dilution are spotted onto YPD, YPD supplemented with $100 \mathrm{mM}$ and $200 \mathrm{mM}$ HU. (B-D) All GFP strains are paraformaldehyde fixed and subjected to fluorescent microscopy analysis to detect the position of GFP-tagged proteins in the cell. $2.5 \mathrm{\mu g} / \mathrm{ml}$ DAPI staining is used for all of the probes to visualize the position of nucleus. The obtained GFP and DAPI signals are analyzed for co-localizations. GFP - Filter set 38HE (Zeiss); DAPI - Filter set 01 (Zeiss); BF - bright field. 
Table 1 List of S. cerevisiae strains used in this study

\begin{tabular}{|c|c|c|}
\hline Strains (ORF name) & Genotype & Source \\
\hline TOF1-GFP (YNL273W) & 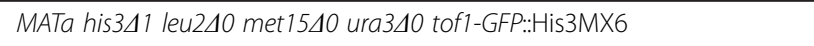 & Invitrogen $^{\mathrm{TM}}$ \\
\hline MRC1-GFP (YCL061C) & MATa his341 leu240 met1540 ura340 mrc1-GFP-HIS3MX6 & Invitrogen ${ }^{T M}$ \\
\hline CSM3-GFP (YMR048W) & MATa his341 leu240 met1540 ura340 csm3-GFP-HIS3MX6 & Invitrogen ${ }^{\mathrm{TM}}$ \\
\hline RAD53-GFP (YPL153C) & MATa his341 leu240 met1540 ura340 rad53-GFP-HIS3MX6 & Invitrogen $^{T M}$ \\
\hline TOF1-GFP; csm3A & MATa his341 leu240 met1540 ura340 tof1-GFP-HIS3MX6 csm34::KanMX & This study \\
\hline TOF1-GFP; mrclA & MATa his341 leu240 met1540 ura340 tof1-GFP-HIS3MX6 mrc14::KanMX & This study \\
\hline CSM3-GFP; tof1A & 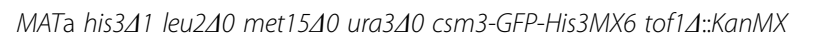 & This study \\
\hline CSM3-GFP; mrc14 & MATa his341 leu240 met1540 ura340 csm3-GFP-HIS3MX6 mrc14::KanMX & This study \\
\hline MRC1-GFP; csm3A & 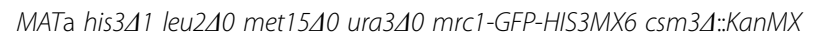 & This study \\
\hline MRC1-GFP; tof1A & MATa his341 leu240 met1540 ura340 mrc1-GFP-HIS3MX6 tof14:KanMX & This study \\
\hline HTB2-mCherry & SLJ3517 (MATa, htb2::HTB2-mCherry-HYGMX) & Sue L. Jaspersen \\
\hline
\end{tabular}

Interdependence of the subunits of the Tof1/Csm3/Mrc1 complex for their chromatin binding

Next we studied the interrelations of the three subunits for the chromatin assembly of the Tof1/Csm3/Mrc1 complex. In order to develop a whole cell study that can permit direct visualization of chromatin attached proteins, we used the same set of strains and carried out a "soft wash" by TritonX-100 detergent of partially spheroplasted S.cerevisieae cells (Methods). The most important step in that procedure was to determine the percentage of detergent to use. First we treated the cells with $100 \mathrm{mM} \mathrm{HU}$ for 3 hours to ensure that the three studied proteins are chromatin bound. Then we tested various amounts of TritonX-100 on every GFP-strain without deletion. The maximum percentage of detergent that does not detach the protein from chromatin and reveal nuclear GFP signal was used for further studies. For $M R C 1-G F P, 0.5 \% \mathrm{w} / \mathrm{v}$ of detergent proved to be appropriate and for TOF1-GFP and CSM3-GFP - 3.0\%. w/v (Figure 2). As a positive control, a strain, carrying HTB2 protein (S. cerevisiae histone $\mathrm{H} 2 \mathrm{~B}$ ) fused with mCherry was also subjected to the same TritonX-100 washing procedure (Additional file 1: Figure S1). This method permitted us to perform simple multichannel fluorescent
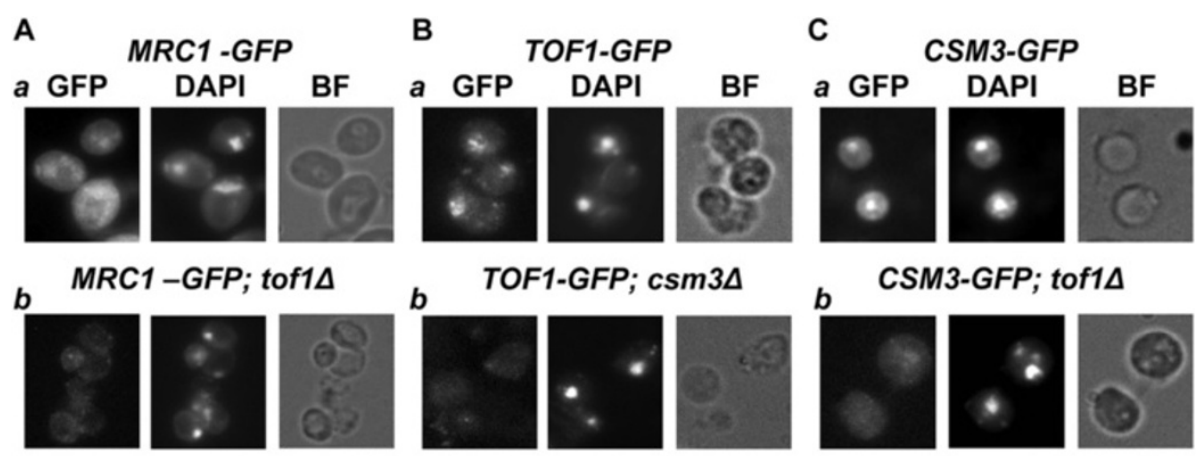

TOF1-GFP; $\operatorname{csm} 3 \Delta$
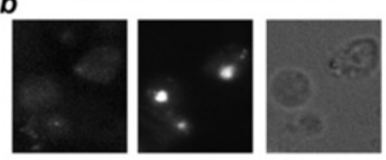

b

CSM3-GFP; tof1A
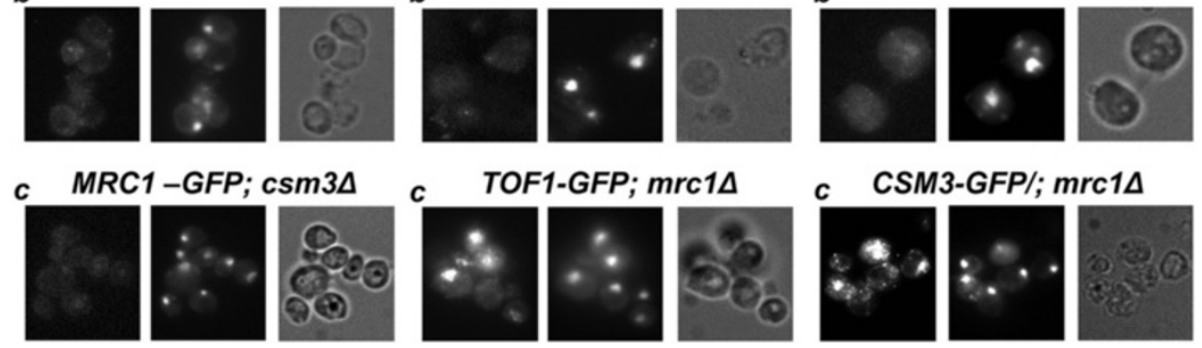

Figure 2 Interdependence of the subunits of the Tof1/Csm3/Mrc1 complex for their chromatin binding. After partial spheroplasting by LongLife $^{\mathrm{TM}}$ Zymolyase ${ }^{\oplus}$, all GFP strains are subjected to soluble proteins washing via TritonX-100 detergent treatment. In all experiments where chromatin binding of Mrc1 is studied, cells are treated with 0.5\% w/v of detergent. When Tof1 or Csm3 are studied, 3.0\% w/v of detergent is used. Cells are paraformaldehyde fixed and subjected to fluorescent microscopy analysis to detect the position of GFP-tagged proteins. $2.5 \mu \mathrm{g} / \mathrm{ml}$ DAPI staining is used for all of the probes to visualize the position of DNA. The obtained GFP and DAPI signals are analyzed for co-localizations. The match of obtained DAPI and GFP signals of TritonX-100 treated MRC1-GFP (A.a), TOF1-GFP (B.a) and CSM3-GFP (C.a) is indicative of their

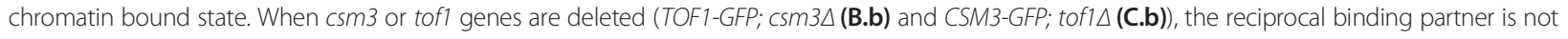
detected on chromatin. After TritonX-100 wash of the soluble proteins from TOF1-GFP; mrc1 $\triangle$ (B.C) and CSM3-GFP; mrc1 $\triangle$ (C.c) strains, the GFP signals coincide with DAPI signals. Both MRC1-GFP; tof1 $\triangle$ (A.b) and MRC1-GFP; csm3 $\triangle$ (A.c) strains, when treated with TritonX-100, demonstrate lack of GFP signal. GFP - Filter set 38HE (Zeiss); DAPI - Filter set 01 (Zeiss); BF - bright field. 
microscopy and direct visualization of the insoluble, chromatin bound GFP-tagged proteins. DAPI staining of the paraformaldehyde fixed cells was carried out. The match of GFP and DAPI signals was analyzed as an indicator of chromatin binding of the GFP-fused protein. As the treatment with TritonX-100 of partially spheroplasted yeast cells leads to cell shape deformations, the compactness of the achieved DAPI signal was also representative of nuclear integrity.

The microscopy revealed that when tof 1 or $\operatorname{csm} 3$ genes are deleted (in CSM3-GFP; tof1 1 or TOF1-GFP; csm3 strains respectively), the reciprocal binding partner was not attached to chromatin (Figure 2), showing that Tof1 and $\mathrm{Csm} 3$ are interdependent for their chromatin binding. In contrast, such a dependence of Tof1 and Csm3 on Mrc1 was not observed. After TritonX-100 wash of the soluble proteins and fluorescent microscopy of the TOF1-GFP; $m r c 1 \triangle$ and CSM3-GFP; $m r c 1 \Delta$ strains, the examined GFP signals coincided with the corresponding DAPI signals (Figure 2). These results show independence of Tof1-Csm3 dimer chromatin binding on Mrc1. In contrast, Mrc1 required intact Tof1-Csm3 complex in order to associate to chromatin (Figure 2).

\section{Mrc1 is positioned in the nucleus throughout the cell cycle}

The three studied proteins co-precipitate together. Interestingly, Tof1 and Csm3 co-precipitate in stoichiometric amounts, but Mrc1 (as well as MCM's complex subunits) is in substoichiometric amounts [7], suggesting that Mrc1 is not constantly attached to Tof1-Csm3 dimer. As the function of Mrc1 is assumed to be restricted to S-phase, when it is DNA bound [33], we checked whether it is positioned in cell nucleus during that phase of the cell cycle only. To check this possibility, we examined the nuclear localization of Mrc1 during the cell cycle. S. cerevisiae exponentially growing MRC1GFP cells were subjected to time-lapse live cell imaging. The obtained results indicated that Mrc1 fluorescent signal is detected in the cell nucleus during the entire cell cycle (Figure 3A, B). These data show that translocation into the nucleus is not the key process to restrict the attachement of Mrc1 to Tof1-Csm3. Probably, some other mechanisms, such as protein-protein and/or protein DNA interactions, as well as degradation of Mrc1 are the responsible mechanisms, which control its complex binding and S-phase functions.

\section{Mrc1 is removed from chromatin when the S-phase checkpoint is overcome in the presence of $\mathrm{HU}$}

Tof1, Csm3 and Mrc1 are all necessary for normal fork progression as well as stable checkpoint fork arrest $[8,45]$, but just Mrc1 is sufficient to guarantee recovery after fork arrest [46]. It was shown that replication forks reveal restart difficulties after HU block in $m r c 1 \Delta$ cells [39]. As Mrc1 is important for stable fork arrest, we decided to check for alterations in the nuclear behavior of Mrc1 in the process of adaptation. The adaptation is a process of overcoming the S-phase checkpoint and is noticed to take place when cells are subjected to persistent agent treatment or impossibility to repair specific DNA damage.

MRC1-GFP cells were treated with 100 mM HU. Samples, starting from the third hour, from indicated time points, were taken and either fixed straight away or washed with TritonX-100 before fixing. The fluorescent microscopy results indicated the presence of Mrc1 at chromatin until 3 h 45 min (Figure 4A, B). Interestingly, the next samples, taken at $4 \mathrm{~h} 30 \mathrm{~min}$ and $4 \mathrm{~h} 45 \mathrm{~min}$ (Figure 4C, D), indicated that Mrc1 was still located in cell nucleus (although its amount seemed to be diminished) but removed from chromatin. Then, after $5 \mathrm{~h}$ $30 \mathrm{~min}$ from $\mathrm{HU}$ addition (Figure 4E), Mrc1 protein seemed to reappear at chromatin. The flow cytometry analysis, carried out with cell probes from the same time points, indicated a small shift towards two contents of DNA (Figure 4F) after $4 \mathrm{~h} 30 \mathrm{~min}$, suggesting that the $\mathrm{S}$-phase checkpoint arrest had been by-passed and that the yeast cells had overcome the ribonucleotide reductase inhibition.

The observed Mrc1 chromatin diminishment was also detected by bulk chromatin fractioning assay (Figure 5A). The Western blot band analysis of that experiment revealed that the amount of chromatin bound Mrc1-GFP protein from $4 \mathrm{~h} 30 \mathrm{~min}$ time point, relative to the protein value from the whole cell extract of the same timepoint, indicated $42 \%$ diminishment, compared to the same correlation from the $3 \mathrm{~h} 00 \mathrm{~min}$ in $100 \mathrm{mM} \mathrm{HU}$ (Figure 5B).

To ensure that cells that proceed throughout the cell cycle in the presence of HU had overcome the S-phase checkpoint arrest, we analyzed the Rad53 kinase. We carried out Western blot analysis of total protein extracts from $100 \mathrm{mM} \mathrm{HU}$ treated yeast MRC1-GFP cells (Figure 4G). The immunodetection indicated (Figure 5C) that as expected, at the third hour $\operatorname{Rad} 53$ appeared to be in hyperphosphorylated state that corresponds to S-phase checkpoint activation. The samples taken later on show that the amount of phosphorylated Rad53 seemed to significantly decrease. Both detachment of Mrc1 from chromatin and the decrease of phosphorylated Rad53 are indicative for S-phase checkpoint escape.

Confirmatory of that S-phase checkpoint escape are the results we obtained from Mrc1-GFP yeast nuclear morphology analysis experiment [47]. Yeast cells, treated with $100 \mathrm{mM} \mathrm{HU}$ as described were DAPI stained and monitored under fluorescent microscope at indicated time points (Figure 5D). At the time of $\mathrm{HU}$ arrest, 79\% 


\section{A}

\section{Live cell imaging of Mrc1-GFP}
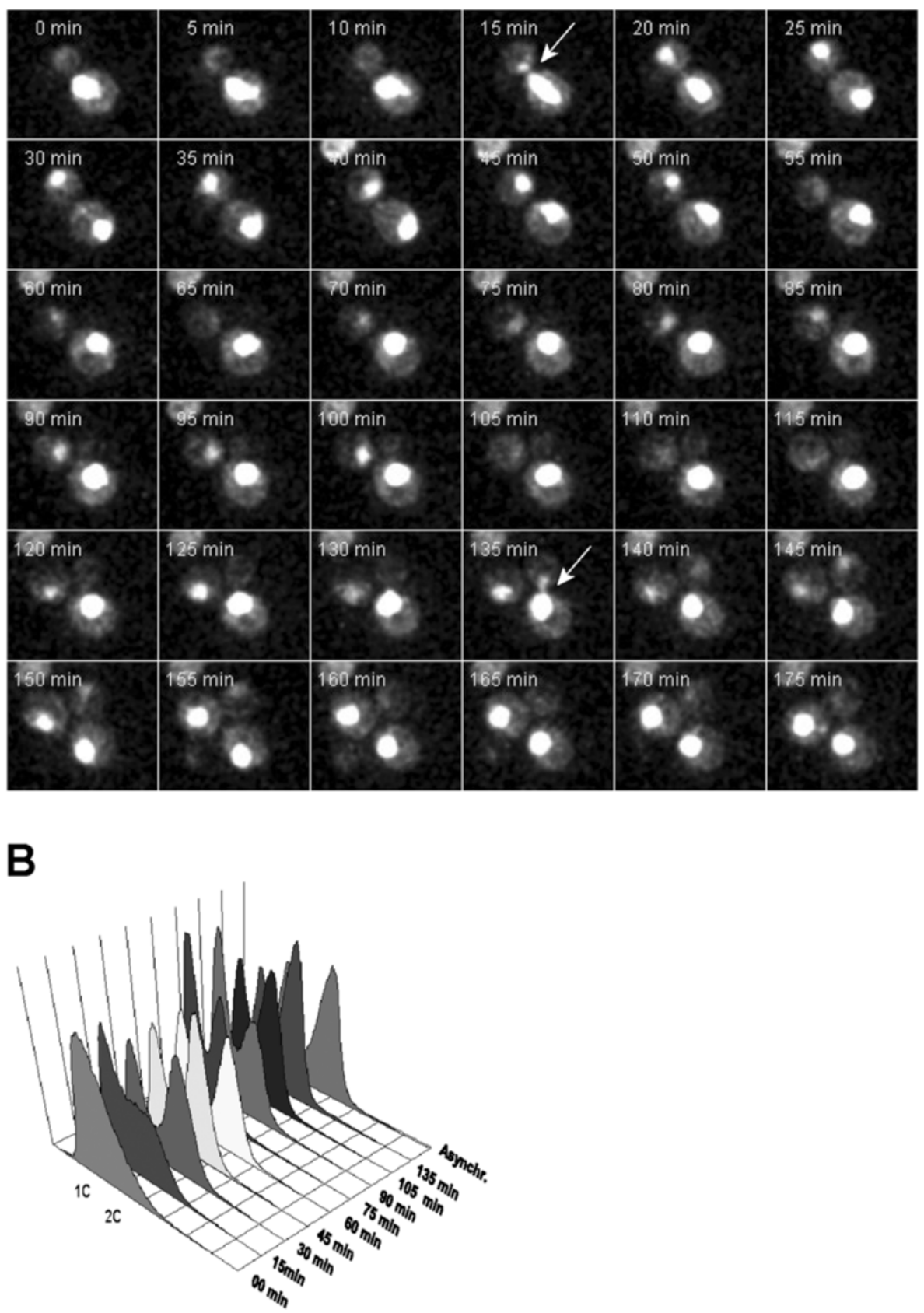

Figure 3 Nuclear presence of Mrc1 throughout the cell cycle. (A) Time-lapse live cell imaging of MRC1-GFP yeast cell throughout the cell cycle. The arrows indicate the characteristic anaphase nuclear morphology of the cell. The frames situated between two arrows encompass of one entire cell cycle. (B) FACS analysis of MRC1-GFP yeast cells after release from $100 \mathrm{mM} \mathrm{HU}$ arrest.

of the counted cells revealed S-phase characteristic cellular and nuclear morphology. In contrast, at $4 \mathrm{~h}$ and 30 min time point, that percentage dropped to $34 \%$. This shows that $45 \%$ of the cells had exited the S-phase, a value close to the calculated $42 \%$ decrease of chromatin bound Mrc1. The rest of the cells indicated G2/M-phase related morphology, indicating that cells were no longer $\mathrm{S}$-phase arrested and are trying to continue the cell cycle (Figure 5D). In addition, to visualize the behavior of studied proteins during S-phase checkpoint escape on a single cell level, we carried out time-lapse live cell microscopy of Mrc1-GFP and Rad53-GFP strains in the 


\section{MRC1-GFP in 100mM HU}

A

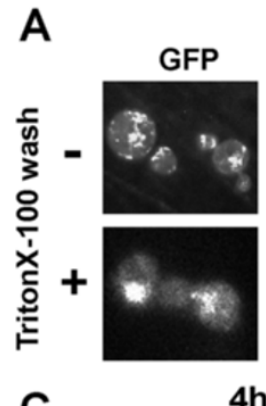

C GFP

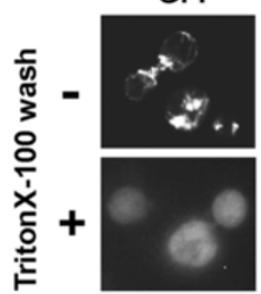

E

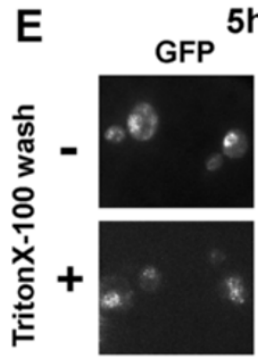

3h in $\mathrm{HU}$

DAPI

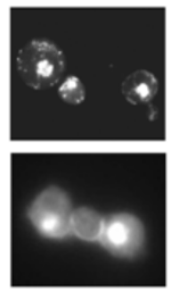

h $30 \mathrm{~min}$ in $\mathrm{HU}$

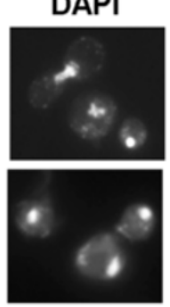

30min in $\mathrm{HU}$

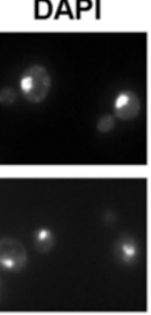

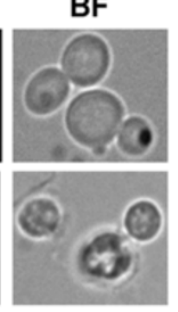

BF

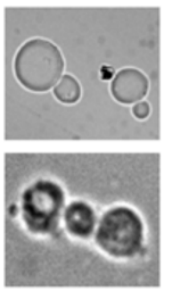

BF

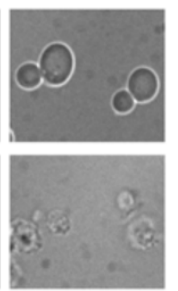

B 3h $45 \mathrm{~min}$ in $\mathrm{HU}$

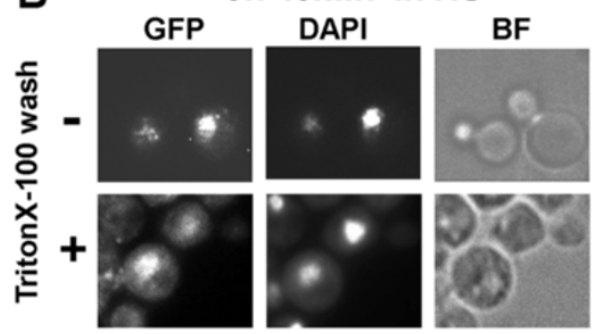

D 4h 45min in $\mathrm{HU}$

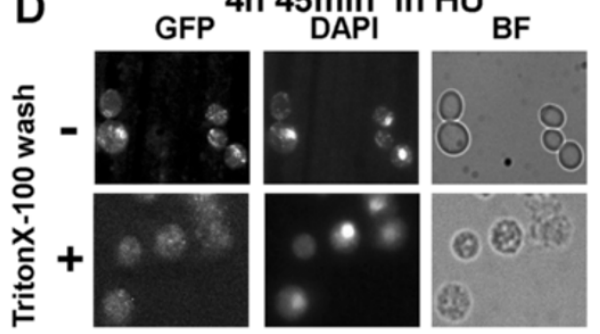

F

Figure 4 Alterations in the nuclear behavior of Mrc1 during the process of adaptation. (A-E) MRC1-GFP probes from indicated tome points, taken in the presence of $100 \mathrm{mM} \mathrm{HU}$. (-) Paraformaldehyde fixed and DAPI stained cells, subjected to multichannel fluorescent microscopy, not washed with detergent. (+) TritonX-100 washed and consequently fixed and DAPI stained probes, observed under fluorescent microscope. GFP - Filter set 38HE (Zeiss); DAPI - Filter set 01 (Zeiss); BF - bright field. (F) FACS analysis of the studied time points in 100 mM HU, indicating a shift towards $2 \mathrm{C}$ after $4 \mathrm{~h}$ and $30 \mathrm{~min}$.

presence of $100 \mathrm{mM} \mathrm{HU}$ (Additional file 1: Figure S2B and $\mathrm{C}$ and Additional file 2: Movie S2 and Additional file 3: Movie S4). The results from those experiments confirmed that cells continue their cell cycle progression in the presence of $\mathrm{HU}$, but the duration of the cell cycle was much longer (compare Additional file 1: Figure S2A with S2B and Figure S2C with Figure 3). Movies of all time-lapse experiments are available in the (Additional file 2: Movie S2, Additional file 3: Movie S4, Additional file 4: Movie S1 and Additional file 5: Movie S3).

To check whether cells can steadily surmount the HU provoked nucleotide deficiency, a HU-viability test was carried out. Samples from MRC1-GFP cells, preliminarily arrested with $\mathrm{HU}(100 \mathrm{mM} \mathrm{HU}$ and $200 \mathrm{mM}$ $\mathrm{HU})$, were taken at indicated time points and grown on plates with or without HU (100 or $200 \mathrm{mM}$ respectively). All samples indicated a visible cell growth (Figure 5E). Not surprisingly, a difference in growth was observed between cells, which after HU preincubation were plated on YPD containing $\mathrm{HU}$ and those - on plates without HU (best visualized after two days of incubation Figure 5E). The results show that all samples, even those, incubated on plates containing $200 \mathrm{mM} \mathrm{HU}$, continued to grow, demonstrating that cells had surmounted the new conditions.

\section{Discussion}

Our study aimed to estimate the interdependencies of the three proteins with regard to compartmentalization of complex assembly. Recent data from other eukaryotes lead to the idea that Tof1/Csm3/Mrc1 complex is assembled in cell cytoplasm. Tanaka and co-workers demonstrated in $S$. pombe that the amount of Mrc1-GFP nuclear signal is significantly reduced when Swi1 or Swi3 is deleted [48]. The authors suggest that the Swi1 and Swi3 are important for Mrc1 nuclear localization and consequent DNA binding. Their results presume that a dimer of Tim-Tipin is assembled in cytoplasm 


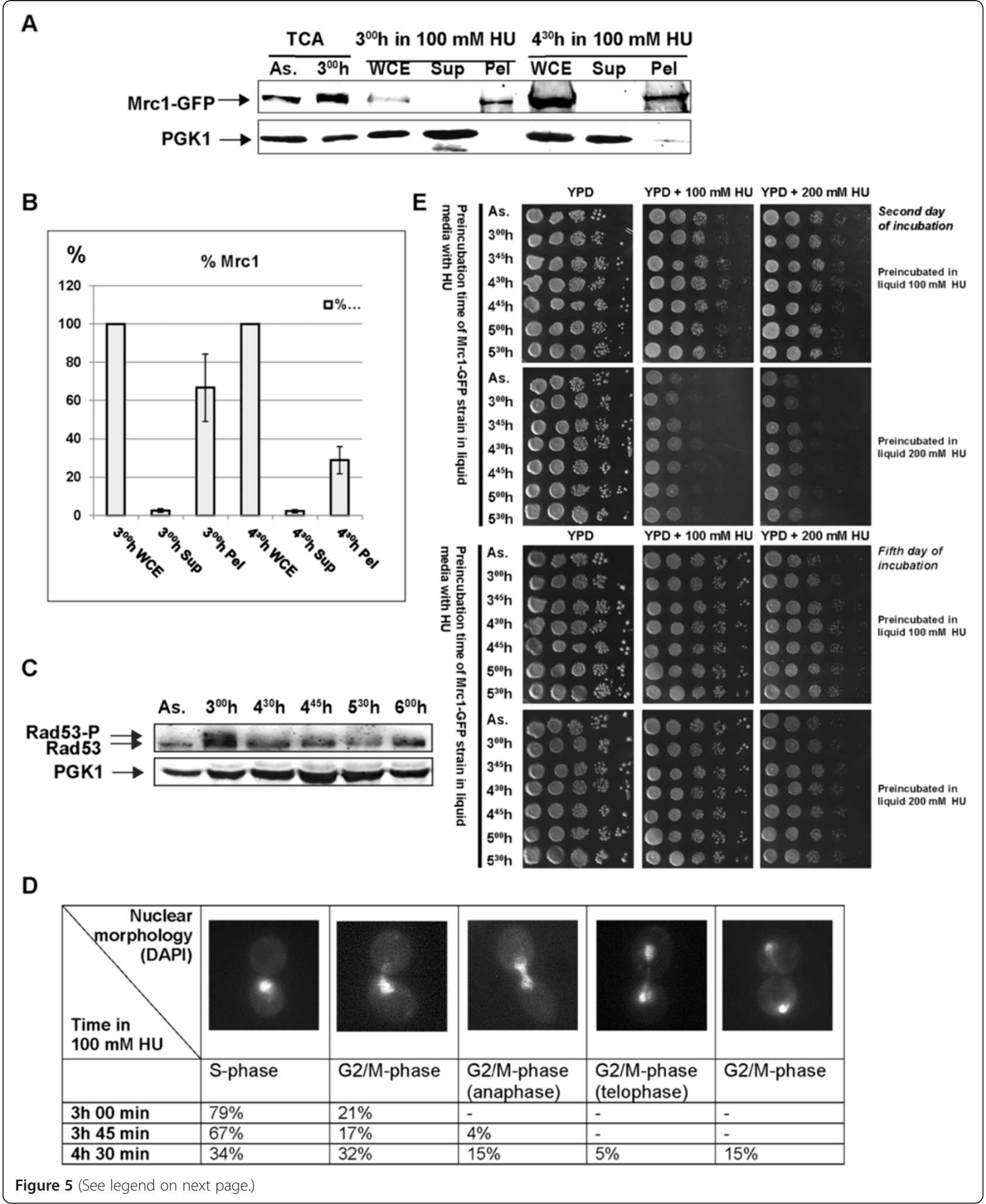


(See figure on previous page.)

Figure 5 Mrc1-GFP cells by-pass the S-phase checkpoint. (A) Bulk chromatin fractioning assay of Mrc1-GFP strain in the presence of 100 mM HU. Samples from indicated time points were fractionated into whole cell extract (WCE), crude soluble (Sup) and chromatin (Pel) fractions. Yeast total protein extracts (TCA) from asynchronous (As.) and treated for three hours ( $3^{00} \mathrm{~h}$ ) with $100 \mathrm{mM} \mathrm{HU} \mathrm{MRC1-GFP} \mathrm{cells} \mathrm{were} \mathrm{run} \mathrm{on} \mathrm{the} \mathrm{same}$ 6-15\% SDS-PAGE. As a control, the cytoplasmic PGK1 protein was monitored on the same Western blotting membrane. (B) The average amount of Mrc1-GFP protein from different Bulk chromatin fractioning assays, measured by the Gel analysis tool of ImageJ software. The measured amount of Mrc1-GFP from the WCE of each time point is assumed as 100\%, the protein from Sup and Pel is calculated as a percentage of respective WCE. Standard deviation of means is indicated as error bars. (C) Total protein extracts from indicated time points from Mrc1-GFP cells in the presence of $100 \mathrm{mM} \mathrm{HU}$. Samples were run on a 6-15\% SDS-PAGE and after western blotting, immunodetections of Rad53 and PGK1 (loading control) were carried out. Rad53-P and Rad53 indicate the phosphorylated and unphosphorylated forms of Rad53 protein. (D) Mrc1-GFP strain nuclear morphology analysis of treated with $100 \mathrm{mM} \mathrm{HU}$ yeast cells. Samples from indicated time points were DAPI stained and monitored under fluorescent microscope. The number of cells with indicated nuclear morphology is given as a percentage of the sum of all counted cells from each sample. (E) Exponentially growing S. cerevisiae cells from MRC1-GFP strain were arrested with $100 \mathrm{mM} \mathrm{HU}$ or $200 \mathrm{mM}$ HU for 3 h in liquid YPD medium and then plated on YPD and YPD, containing 100 or $200 \mathrm{mM}$ HU respectively at indicated time points. The duration of incubations is indicated.

and is responsible for the nuclear translocation of Mrc1. In HeLa cells, when Tim or Tipin were knocked-down, the respective binding partner was relocated to cytoplasm. In addition, the amount of that partner was significantly reduced [49]. Such dependence for Claspins's amount was not found for asynchronous growing cells. But when Tim or Tipin siRNA treated cells were subjected to HU, the amount of nuclear Claspin seemed to diminish. The authors suggest that Tim and Tipin facilitate Claspin nuclear localization under replication stress.

To check whether the complex is formed in the cytoplasm in S. cerevisiae, we studied the cellular localization of GFP-tagged subunits of Tof1/Csm3/Mrc1, when the complex is intact and when a subunit is missing. As in higher eukaryotes [49], our analysis revealed a hypothetical NLS for Tof1, suggesting its responsibility for the nuclear translocation of the other subunits of the complex. However, in contrast to higher eukaryotes, independence with regard to nuclear translocation of all three subunits was observed. Our findings demonstrate that in contrast to $S$. pombe and human cells, the $S$. cerevisiae Tof1/Csm3/Mrc1 S-phase checkpoint complex is most probably assembled in cell nucleus, as every subunit can enter it independently of the others. Deletion of each of the three genes did not lead to cytoplasmic accumulation of any partner subunit. The amounts of the undeleted, GFP-tagged proteins also seemed to be unaffected when observed under fluorescent microscope. As budding yeast is a preferred model organism for replication studies, such a difference in proteins relationships and cell positioning control must be taken into account. As yeast cell nucleus is not disassembled during cell division, but undergoes nuclear division into two daughter nuclei, it might be speculated that those differences in the localization of complex assembly are a result of evolutionary adaptation and management of higher eukaryotes.

As Tof1, Csm3 and Mrc1 enter nucleus independently in S. cerevisiae, a question about the mechanism of complex assembly arises. The stoichiometric interaction of Tof1 and Csm3 (in co-precipitation experiments on asynchronous cultures) indicates that by default they form a heterodimer (Nedelcheva et al. [7]). In contrast, the non- stoichiometric amount of Mrc1 suggests that it joins the complex occasionally. Is then the Tof1-Csm3 dimer formation required to ensure attachment to chromatin and how is Mrc1 related to those relationships? In higher eukaryotes data are variable in accordance with the model system applied in the study. The Xenopus egg extract data show that Tipin and Claspin fail to bind to chromatin when Tim1 is depleted and that Tim1-Tipin is required for binding of Claspin but not vice versa [50]. In HeLa cells Tim and Tipin are interdependent for their chromatin binding [49], but insoluble Claspin is not affected by Tipin siRNA in asynchronous culture. Such dependence is noticed in HU treated cells only.

To visualize the chromatin association and dependencies of the subunits via a whole cell approach, we adapted the higher eukaryotes protocol for in situ chromatin binding assay [36,37] to $S$. cerevisiae. This method permits performance of direct multichannel fluorescent microscopy to visualize the insoluble, chromatin bound GFP-tagged proteins. The results demonstrate the necessity of Tof 1 for the chromatin binding of Csm3 and vice versa. Our results also show that Mrc1 is Tof1 and Csm3 dependent for its chromatin association, but in contrast, Mrc1 is not required for the chromatin binding of Tof1 and Csm3. These data are in unison with ChIP-chip results of Bando and co-workers for the co-dependences of those proteins for association with replication forks [1].

It can be summarised that in S. cerevisiae Tof1-Csm3 initial dimer formation is required for chromatin association. The nuclear import is not a regulatory step as every single subunit enters the nucleus independently. As a dimer Tof1-Csm3 is responsible for the chromatin binding of Mrc1.

A logical question to answer in that relation is whether the controlling mechanism for the restricted binding of 
Mrc1 to the Tof1 - Csm3 dimer (as co-precipitations indicated) is a result of cell cycle oscillations of its cellular localization. As Mrc1 known functions are restrained to $\mathrm{S}$-phase of the cell cycle, when it is DNA bound [33], we checked whether it is positioned in cell nucleus during that phase of the cell cycle only. Our results indicated that there is nuclear Mrc1 during the entire cell cycle, confirming that translocation into the nucleus is not the leading process to regulate the association of Mrc1 to the S-phase checkpoint complex. A regulatory function of the timing of Mrc1's triple S-phase complex association can be suggested, but further studies are required to elucidate the fine mechanisms of these interactions.

All three proteins Tof1, Csm3 and Mrc1 are involved in normal fork progression and stable checkpoint fork arrest $[8,45]$, but just Mrc1 is assumed to be responsible for fork rehabilitation after fork arrest [39]. Stalled forks restart much harder in mrc1 $\Delta$ cells when $\mathrm{HU}$ is removed from the media, suggesting a role for Mrc1 to promote stable fork-pausing complex formation and to guarantee recovery after fork arrest. Some recent data connect Mrc1 with $\mathrm{SCF}^{\mathrm{Dia} 2}$. This interaction was shown to be responsible for destabilization of Mrc1 in a proteasome-dependent manner during S-phase of the cell cycle in vivo [29]. It was also demonstrated that Dia2 contributes to Mrc1 degradation during S-phase checkpoint recovery [46]. As Mrc1 is important for stable fork arrest, we checked for alterations in the nuclear behavior of the protein in the process of overcoming the S-phase checkpoint, called adaptation. Generally, the adaptation is a process of loosening the S-phase checkpoint when cell meets impediments for coping with persistent agent or damage. The reason for such cell decision is not quite clear. It was suggested that when the cell is unable to cope with the problem, it allows restoration of the cell cycle to provide opportunities to repair the damage in a subsequent cell cycle, enhancing its chances for survival. The intimate mechanisms of executing and controlling this phenomenon are still vague. Some data point out the specific role of the amount of polo-like kinase CDC5 to suppress the hyperphosphorylation of $\operatorname{Rad} 53$ that leads to relieve of cell division arrest [51,52].

We studied the nuclear behavior of Mrc1 after a prolonged period of incubation in the presence of HU. The fluorescent microscopy results in combination with flow cytometry data and bulk chromatin fractioning indicated that when the $S$. cerevisiae cell by-passes S-phase checkpoint arrest (after $4 \mathrm{~h}$ and $30 \mathrm{~min}$ ) to proceed further into the cell cycle in the presence of the blocking agent, Mrc1 dissociates from chromatin. This finding emphasizes the specific role of Mrc1 for keeping the stability of forks arrest. It shows that the physical presence of Mrc1 at replication pausing complex is required not only for stable fork arrest in response to $\mathrm{S}$-phase checkpoint agent, but for the duration of that arrest as well.
In support of our findings, cell free studies on Xenopus egg extract in aphidicolin-induced DNA replication block show that after a prolonged interphase arrest, the extracts undergo adaptation and enter into mitosis with unfinished DNA replication. In this process Chk1 undergoes inactivation and Claspin dissociates from chromatin [53].

One of the major functions of the S-phase checkpoint is to sufficiently enlarge the nucleotide pool in the cell [54]. The key enzyme to regulate the levels of dNTPs ribonucleotide reductase (RNR) is regulated by the Mec1/Rad53/Dun1 kinases via two different mechanisms $[55,56]$. The first one aims the transcriptional induction of the RNR genes and the second results in phosphorylation and removal of the RNR inhibitor Sml1 $[57,58]$. When HU is introduced into the media, it provokes the $\mathrm{S}$-phase checkpoint activation that results in Sml1 degradation and free nucleotide pool enlargement. On the other hand, the HU itself is an inhibitor of RNR and effects limitation of the amount of dNTPs. Therefore, the net effect of the two counteractive processes is measured and the predominant process takes control over cell fate, directing it either towards nucleotide synthesis or towards nucleotide synthesis inhibition. The dose of HU itself might be of major importance to target the process. In our experiments $100 \mathrm{mM} \mathrm{HU}$ was used. Our FACS analysis (Figures $3 \mathrm{~B}$ and $4 \mathrm{~F}$ ) and the phosphorylation of $\operatorname{Rad} 53$ at the third hour of $\mathrm{HU}$ treatment (Figure 5C) indicate that the amount of HU used provokes S-phase checkpoint activation. At the same time, the live-cell imaging of Rad53-GFP and Mrc1-GFP cells (Additional file 1: Figure S2), as well as the viability test that we carried out (Figure 5E) undoubtedly indicate that yeast cells somehow succeed to survive and grow in 100 and even $200 \mathrm{mM} \mathrm{HU}$ for a long period of time. This shows that the decision for cell arrest was abolished and probably the nucleotide levels were sufficiently adequate to allow cell cycle restoration. Interestingly, the ordinary dynamics of the cell cycle is not absolutely restored. Alvino and co-workers [59] as well as our timelapse live cell imaging experiments indicate that the duration of the cell cycle in $\mathrm{HU}$ is much longer than the ordinary one. A probable explanation is that cells adapt to $\mathrm{HU}$ by raising the level of nucleotides to permit progression of the cell cycle, but those levels remain limited and do not allow full restoration of the dynamics of the cell cycle. How the cell weighs the two opposite effects of the HU on the dNTPs pool and takes its decisions is still unclear. Many other experimental data are required to establish the mechanisms of this decision making. Our results indicate that the detachment of Mrc1 from chromatin and the diminishment of Rad53 phosphorylation give a proof of S-phase checkpoint bypass that follows that adaptation.

Our results demonstrate that in the living cell, during $\mathrm{S}$-phase checkpoint adaptation, Mrc1 is removed from 
chromatin. One possible explanation for that detachment is the specific role of Mrc1 to prevent replicative helicase movement when the polymerase meets an obstacle for correct DNA synthesis. We hypothesize that the pausing structure is possible when a "clutch" of Mrc1 on MCM is present. This clutch is required for docking Mecland Rad53 to ensure their checkpoint kinase activities, leading to fork arrest. Via some regulatory mechanisms (perhaps by means of Polo-like kinase attachment and consequent phosphorylation) Mrc1 is dissociated from chromatin by detachment or degradation. The lack of Mrc1 leads to loss of Rad53/Mrc1 activity and loosens MCM helicase (Figure 6). As Mrc1 is required for normal replication fork progression, later on, when the cell division arrest has been relieved, the protein rebinds Tof1-Csm3 to ensure DNA synthesis.

\section{Conclusions}

Our findings demonstrate that in contrast to S. pombe and human cells, the $S$. cerevisiae Tof1/Csm3/Mrc1 $\mathrm{S}$-phase checkpoint complex is most probably assembled in cell nucleus, as every subunit can enter it independently and deletion of each of the three genes did not lead to cytoplasmic accumulation of any partner subunit.
Our data also indicates that in S. cerevisiae Tof1-Csm3 initial dimer formation is required for chromatin association of Mrc1. This process is not controlled by the cell cycle as the protein is constantly positioned in the nucleus.

Our results indicate that in the process of adaptation to the presence of HU Mrc1 is detached from chromatin to relax Rad53 activity and thus to allow completion of the cell cycle. Our study emphasizes the specific role of Mrc1 for keeping the stability of fork arrest. It shows that the physical presence of Mrc1 at replication pausing complex is required not only for stable fork arrest in response to S-phase checkpoint agent, but also for the duration of that arrest.

\section{Methods}

\section{Strains and media}

S. cerevisiae strains (Invitrogen ${ }^{\mathrm{\tau \mu}}$, Cat.\# 95702) YNL273W

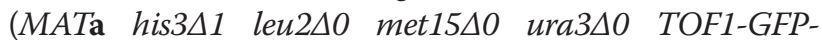
HIS3MX6), YCL061C (MATa his3 11 leu2 $\triangle 0$ met15 $\Delta 0$ ura3 $\triangle 0$ MRC1-GFP-His3MX6), YMR048W (MATa his3 1

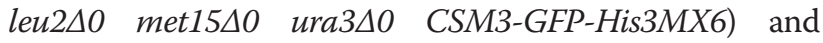

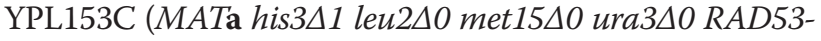
GFP-HIS3MX6) are used [44]. We refer to those strains as

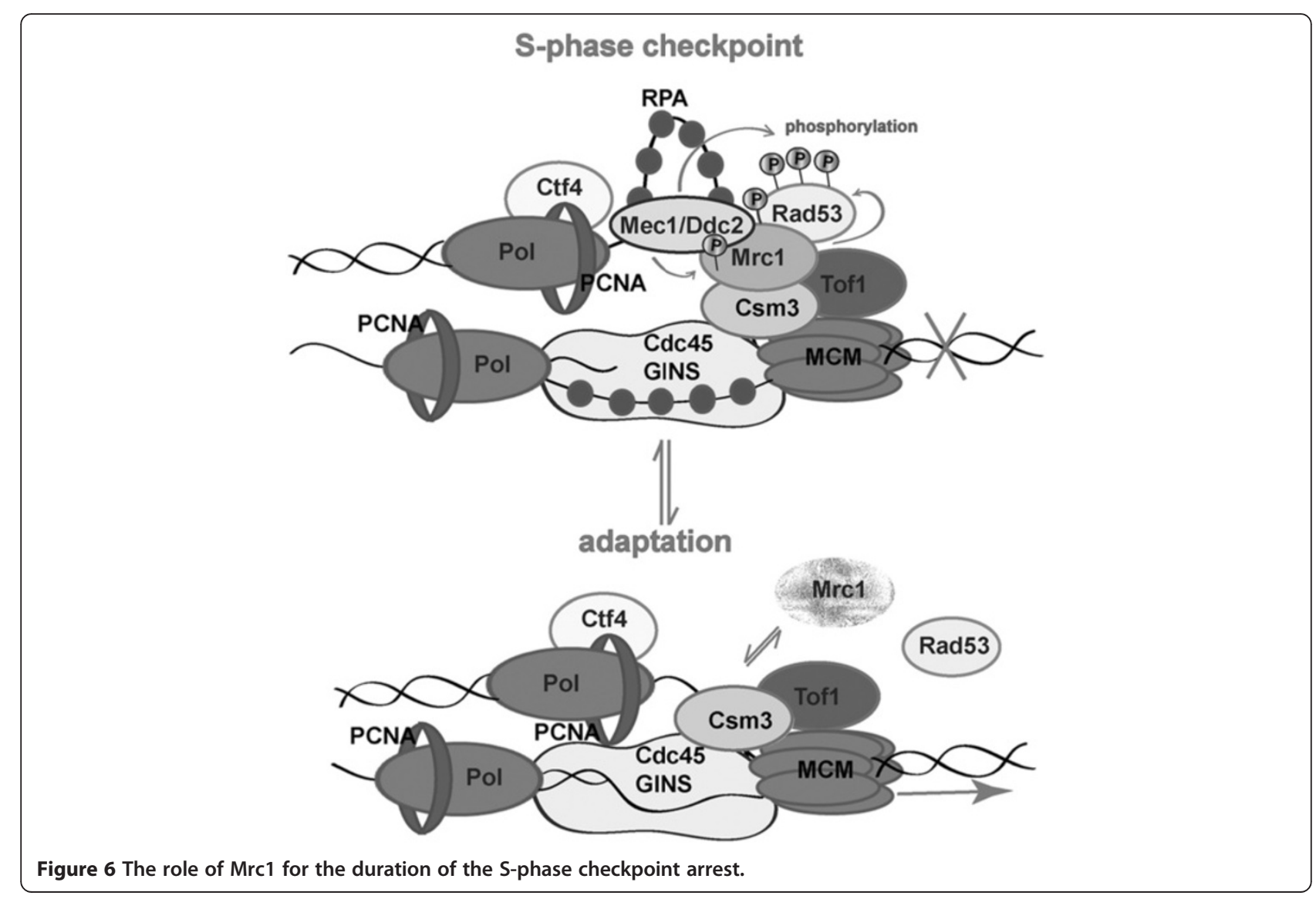


TOF1-GFP, MRC1-GFP, CSM3-GFP and RAD53-GFP, respectively. All are with BY 4741 background. We used YNL273W, YCL061C and YMR048W to delete a gene coding a partner subunit of the $\mathrm{S}$-phase checkpoint complex Tof1/Csm3/Mrc1 that is not GFP-tagged. As a control for in situ chromatin binding assays SLJ3517 (MATa, htb2::HTB2-mCherry-HYGMX) or shortly - HTB2$m$ Cherry, was used. All strains are listed in Table 1. Strains were cultivated in YPD medium $(1 \%(\mathrm{w} / \mathrm{v})$ yeast extract (Difco), 2\% (w/v) Bacto peptone (Difco), 2\% (w/v) dextrose). Before fluorescent and confocal microscopy procedures, yeast cells were grown in minimal medium (1.7 g/l YNB, 0.04 g/l CSM-His (Bio101, Inc.) and 2\% $(\mathrm{w} / \mathrm{v})$ dextrose) to diminish the autofluorescence.

\section{Construction of strains}

The plasmid pKS-KanMX6-1 (4571 bp) was used to PCR amplify the disruption cassettes for tof $1, \operatorname{mrc} 1$ and $\operatorname{csm} 3$. For construction of the disruption cassettes, primers 1-6 were used (Table 2). These cassettes contained a selection marker KanMX for geneticine (G418) resistance. The disruption cassettes carried 50 bp flanking sequences (introduced by the PCR primers) homologous to regions, which surround the target genes. Strains TOF1-GFP, MRC1-GFP and CSM3-GFP were transformed with the respective cassette [60]. The selection for integration was carried out on YPD medium, containing $200 \mu \mathrm{mol} / \mathrm{ml} \mathrm{G418.} \mathrm{The} \mathrm{inte-}$ gration of the disruption cassette was also confirmed by diagnostic PCR [61]. The pairs of primers used in these reactions were designed so that one of them is complementary to the sequence from the KanMX gene, and the other - to the yeast genome region, neighboring the integrated cassette (Table 2).

\section{GFP-fixation}

A protocol published at "Koshland Web Site/Methods" was applied http://mcb.berkeley.edu/labs/koshland/Protocols/ MICROSCOPY/gfpfix.html. $250 \mu \mathrm{l}$ of S. cerevisiae cells were resuspended in $100 \mu \mathrm{l}$ of paraformaldehyde/sucrose
(4 g paraformaldehyde, $3.4 \mathrm{~g}$ sucrose in $100 \mathrm{ml}$ water). After $15 \mathrm{~min}$ of room temperature incubation, cells were washed and resuspended in appropriate quantity of KPO4/ sorbitol (2 M sorbitol, $1 \mathrm{M} \mathrm{KPi,} \mathrm{pH} 7.5$ (made of $183.4 \mathrm{ml}$ $1 \mathrm{M} \mathrm{K}_{2} \mathrm{HPO}_{4}$ and $16.6 \mathrm{ml} 1 \mathrm{M} \mathrm{KH}_{2} \mathrm{PO}_{4}$ ) and $\mathrm{H}_{2} \mathrm{O}$ in a 6:1:3 proportion).

\section{Fluorescent microscopy}

Glass slides were covered with $0.1 \% \mathrm{w} / \mathrm{v}$ Poly-L-Lysine solution (SIGMA-ALDRICH, No. P 8920). $2.5 \mu \mathrm{g} / \mathrm{ml}$ of DAPI (SIGMA-ALDRICH, No. 9542) was added to the fixed cells. They were incubated at $30^{\circ} \mathrm{C}$, for $15 \mathrm{~min}$ in dark. Yeast cells were pelleted and washed in $1 \times \mathrm{PBS}$ (137 mM NaCl, $2.7 \mathrm{mM} \mathrm{KCl,} 4.3 \mathrm{mM} \mathrm{Na}{ }_{2} \mathrm{HPO}_{4}, 1.4 \mathrm{mM}$ $\mathrm{KH}_{2} \mathrm{PO}_{4}$ ). After resuspending in $1 x \mathrm{PBS}$, they were ready for DNA nuclear observation. $5 \mu$ cell suspension was pipetted onto the slide and after $10 \mathrm{sec}$ deposition, covered with coverslip. Observations are made by EC-Plan Neofluar $100 \times / 1.3$ Oil-immersion objective mounted on a Axiovert $200 \mathrm{M}$ inverted fluorescent microscope, Carl Zeiss, using AxioCam MRm CCD camera, Carl Zeiss and filters: Filter set 01 (excitation: BP 365/12; beamsplitter: FT 395; emission: LP 397) and Filter set 38HE (excitation: BP 470/40; beamsplitter: FT 495; emission: BP 525/50). Images were acquired and processed by Carl Zeiss AxioVision Rel.4.7 and ImageJ software.

\section{Time-lapse live cell imaging experiments}

The glass-slide part of the "Glass bottom dishes" (Mattech, \#s: P50G-1.5-14-) was covered with 0.1\% w/v Poly-LLysine solution (SIGMA-ALDRICH, No. P 8920) in order to mount the yeast cells. To diminish the autofluorescence, the yeast cells were grown in minimal medium $(1.7 \mathrm{~g} / \mathrm{l}$ YNB, 0.04 g/l CSM-His (Bio101, Inc. and 2\% (w/v) dextrose) with $20 \mu \mathrm{g} / \mathrm{ml}$ extra adenine. All procedures were carried out at $25^{\circ} \mathrm{C}$ and according to the protocol, described by Silva and co-workers [62] (Cite). Observations were made by CFI Apo TIRF 100X Oil 1.49 NA objective mounted on Yokogawa CSU-X1 spinning disc confocal

Table 2 PCR primers used in this study

\begin{tabular}{|c|c|c|}
\hline Primer & Aplication & Sequence \\
\hline scm3 F & Gene disruption & TACTGGATTAAAATGCCATGAAAACGTGAACAGAAACTITTATTGAGGTCCACTCAACCCTATCTCGG \\
\hline $\operatorname{csm} 3 \mathrm{R}$ & Gene disruption & TATAGATGCCCACACGCACGTTTGGATTATTACCTTCAATGACATTGCTACTCGAAATTAACCCTCAC \\
\hline $\operatorname{mrcl} F$ & Gene disruption & CTAAGGAAGTTCGTTATTCGCTITGAACTTATCACCAAATATTTAGTGCACTCAACCCTATCTCGG \\
\hline mrcl R & Gene disruption & GACAGCTTCTGGAGTTCAATCAACTTCTTCGGAAAAGATAAAAAACCACTCTCGAAATTAACCCTCAC \\
\hline tof1 $F$ & Gene disruption & CATCTAGCTTGTGGGGTITAGTGTATCITAATATAGGAGGGCGCACACTCACTCAACCCTATCTCGG \\
\hline tof1 R & Gene disruption & TTCTAAAATTACACGTATTAAAGGGATTAATTACTACATATTCATTCTCACTCGAAATTAACCCTCAC \\
\hline KanMX-check & Diagnostic PCR & GTCACCTAAATCGTATGT \\
\hline $\operatorname{csm} \Delta$-check & Diagnostic PCR & ATCGTITGACAAGAGAGT \\
\hline $\operatorname{mrc1} \Delta$-check & Diagnostic PCR & TCAAATGTCCAAGTGAAC \\
\hline tof1 $\Delta$-check & Diagnostic PCR & GAAGAAGTTACTCCAAGA \\
\hline
\end{tabular}


microscope (Andor Revolution XD system with Nikon TiE microscope stand and incubator for temperature and humidity control). Data were documented by iXon 897EMCCD camera with TiCAM. All time-lapse experiments were run using the following parameters: 11 Z-stacks, $0.5 \mu \mathrm{m}$ apart, acquired with $18 \%$ laser power on $488 \mathrm{~nm}$ and $200 \mathrm{~ms}$ exposure. Acquisition was made on every $5 \mathrm{~min}$ for $12-16 \mathrm{~h}$. Maximum intensity projections of the stacks were prepared using ImageJ. Images and movies were processed by ImageJ software.

\section{In situ chromatin binding assay}

First the procedure was done on Mrc1-GFP, Tof1-GFP and Csm3-GFP strains. Cells were treated with $100 \mathrm{mM} \mathrm{HU}$ for 3 hours to ensure that the three GFP-fused proteins are chromatin bound. The cells were washed and resuspended in Spheroplasting buffer (0.1 M KPi, pH 7.5 described above; $1.2 \mathrm{M}$ sorbitol; $0.5 \mathrm{mM} \mathrm{MgCl}_{2}$ ). $2 \%$ of beta-mercapto-ethanol, diluted 1:10, was added and cells were incubated for $7 \mathrm{~min}$ at $30^{\circ} \mathrm{C}$. $4.0 \mu \mathrm{l}$ of LongLife ${ }^{\mathrm{mm}}$ Zymolyase $^{\circ}$ (Geno Technology,Inc; Cat. \# 786-036) [1.5 U/ $\mu \mathrm{l}]$ was added and incubation at $37^{\circ} \mathrm{C}$ for $13 \mathrm{~min}$ was carried out. After centrifugation, spheroplasts were resuspended in Spheroplasting buffer, containing protease inhibitors (Complete Mini EDTA-free tablete, Roche) and various amounts of TritonX-100 were tested for every strain. The maximum percentage of detergent that does not detach the protein from chromatin and reveal nuclear GFP signal was used for further studies. For MRC1-GFP, $0.5 \% \mathrm{w} / \mathrm{v}$ of detergent proved to be appropriate and for TOF1-GFP and CSM3-GFP - 3.0\%. w/v. After incubation with TritonX-100 at $20^{\circ} \mathrm{C}$ for $7 \mathrm{~min}$, cells were washed in Spheroplasting buffer containing protease inhibitors, spun down at $3000 \mathrm{rpm}$ and resuspended in paraformaldehyde/ sucrose for GFP-fixation as described above, avoiding vigorous shaking. To study the other S. cerevisiae GFP strains with deletions, asynchronous cell cultures were used.

\section{Spot assays}

For 10-fold serial dilutions assays, yeast samples were prepared from exponentially growing cultures with concentration $3.4 \times 10^{6}$ cells $/ \mathrm{ml}$. $5 \mu \mathrm{l}$ of each dilution were then spotted onto YPD and YPD supplemented with $100 \mathrm{mM}$ and $200 \mathrm{mM}$ hydroxyurea (HU). Plates were incubated at $25^{\circ} \mathrm{C}$ for 3 days.

For $\mathrm{HU}$ viability test, exponentially growing $S$. cerevisiae cells from MRC1-GFP strain were arrested with $100 \mathrm{mM}$ $\mathrm{HU}$ or $200 \mathrm{mM}$ HU in liquid YPD medium. Aliquots, containing $3.4 \times 10^{6}$ cells $/ \mathrm{ml}$ were taken at indicated time points. 10-fold serial dilutions were prepared and $5 \mu \mathrm{l}$ of each dilution were spotted onto YPD and YPD, containing 100 or $200 \mathrm{mM} \mathrm{HU}$, respectively. Plates were incubated at $25^{\circ} \mathrm{C}$ for 5 days.

\section{Bulk chromatin fractionation}

Whole cell, soluble and chromatin fractions were prepared as previously described [63], with modifications. $1 \times 10^{9}$ cells from logarithmic, $100 \mathrm{mM} \mathrm{HU}$ treated culture were harvested and $0.1 \% \mathrm{NaN}_{3}$ was added. After incubation for $5 \mathrm{~min}$ at $30^{\circ} \mathrm{C}$ cells were treated with $3 \mathrm{ml}$ of prespheroplasting buffer [100 mM PIPES (pH 9.4), $10 \mathrm{mM} \mathrm{DTT]} \mathrm{for} 10 \mathrm{~min}$ and then in $2 \mathrm{ml}$

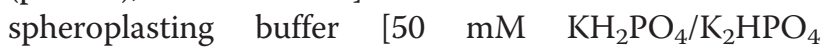
(pH 7.5), 0.6 M Sorbitol, $10 \mathrm{mM} \mathrm{DTT].} \mathrm{After} \mathrm{LongLife}{ }^{\text {tm }}$ Zymolyase $^{\circ}$ (Geno Technology,Inc; Cat. \# 786-036) digestion, the spheroplast pellets were washed with $1 \mathrm{ml}$ of ice-cold wash buffer [100 mM KCl, $50 \mathrm{mM}$ HEPES$\mathrm{KOH}$ (pH 7.5), $2.5 \mathrm{mM} \mathrm{MgCl}$, and 0.4 M Sorbitol], pelleted at $4000 \mathrm{rpm}$ for $1 \mathrm{~min}$ at $4^{\circ} \mathrm{C}$, and resuspended in an equal to the resultant pellet volume of extraction buffer [EB; $100 \mathrm{mM} \mathrm{KCl}, 50 \mathrm{mM}$ HEPES-KOH (pH 7.5), $2.5 \mathrm{mM} \mathrm{MgCl} 2,50 \mathrm{mM} \mathrm{NaF}, 5 \mathrm{mM} \mathrm{Na} \mathrm{P}_{2} \mathrm{O}_{7}, 0.1 \mathrm{mM}$ $\mathrm{NaVO}_{3}$ ], containing $1.5 \%$ Triton $\mathrm{X}-100,1 \mathrm{mM}$ PMSF and protease inhibitors cocktail (cOmplete Mini EDTAfree Protease Inhibitor Cocktail Tablets, \# 05892791001, Roche)]. The suspension was divided into two equal parts - one for whole cell extract (WCE) and the second for crude soluble (Sup) and chromatin (Pel) fractions. After $10 \mathrm{~min}$ incubation at $4^{\circ} \mathrm{C}$, the lysates were passed through a thin syringe needle and spun at $300 \times \mathrm{g}$ in order to pellet and discard the aggregated and unlyzed cells. The Sup + Pel fraction lysate was underlayered with $50 \%$ volume of $30 \%$ sucrose and spun at $12000 \mathrm{rpm}$ for $10 \mathrm{~min}$ at $44^{\circ} \mathrm{C}$. The supernatant (Sup) was kept for soluble fraction. Pellet was washed with $25 \%$ volume of $\mathrm{EB}$ containing $1.5 \%$ Triton X-100 (EBX), and spun again at $10000 \mathrm{rpm}$ for $5 \mathrm{~min}$ at $4^{\circ} \mathrm{C}$. The crude chromatin pellet was dissolved in EBX. Finally, the volumes of WCE, Sup and Pel were equalized with EBX and $2 \times$ Laemmli's buffer was added to each fraction. Samples were boiled for $3 \mathrm{~min}$, and spun at $10000 \mathrm{rpm}$ for $1 \mathrm{~min}$ before loading to $6-15 \%$ gradient SDS PAGE gels.

\section{Western blotting}

Yeast total protein extracts were prepared according to Foiani and co-workers by means of TCA precipitation [64]. All solutions contained protease inhibitors cocktail (cOmplete Mini EDTA-free Protease Inhibitor Cocktail Tablets, \# 05892791001, Roche) and the phosphatase inhibitors $0.1 \mathrm{mM} \mathrm{Na}_{3} \mathrm{VO}_{4}$ and $1 \mathrm{mM} \mathrm{NaF}$. The protein aliquots were loaded on 6-15\% gradient SDS-PAGE and run on $140 \mathrm{~V}$. The samples were transferred onto Protran nitrocellulose membrane and immunodetected using goat polyclonal anti Rad53 antibody (Rad53 y-19 from Santa Cruz Biotechnology, Santa Cruz, CA). The results were visualized on Odyssey Infrared Imaging system (Li-Cor) by means of IRDye 680RD Donkey AntiGoat Antibody (\# 926-68074, Li-Cor). For detection of 
Mrc1 protein, mouse monoclonal Anti-GFP Antibody (\# 11814460 001, Roche) and IR Dye 800CW Goat AntiMouse Antobody (\#926-32210, Li-Cor) were used. PGK1 was immunodetected by mouse monoclonal anti-PGK1 antibody [22C5D8] (ab113687, Abcam) and IR Dye 800CW Goat Anti-Mouse Antobody (\#926-32210, Li-Cor).

\section{Additional files}

Additional file 1: Figure S1. Treating of HTB2-m Cherry S. cerevisiae strain with various amounts of detergent. Figure S2. Cells continue the cell cycle progression in the presence of $\mathrm{HU}$, but the duration of the cell cycle is prolonged.

Additional file 2: Movie S2. Live cell imaging of Mrc1-GFP in $100 \mathrm{mM}$ HU. Time-lapse live cell imaging of MRC1-GFP yeast cells in the presence of $100 \mathrm{mM} \mathrm{HU}$.

Additional file 3: Movie S4. Live cell imaging of Rad53-GFP in $100 \mathrm{mM}$ HU. Time-lapse live cell imaging of Rad53-GFP yeast cells in the presence of $100 \mathrm{mM} \mathrm{HU}$.

Additional file 4: Movie S1. Live cell imaging of Mrc1-GFP. Time-lapse live cell imaging of MRC1-GFP yeast cell throughout the cell cycle.

Additional file 5: Movie S3. Live cell imaging of Rad53-GFP. Time-lapse live cell imaging of Rad53-GFP yeast cell throughout the cell cycle.

\section{Abbreviations}

HU: Hydroxyurea; WT: Wild type; MCM: Minichromosome maintenance proteins; NLS: Nuclear Localization Signals; GFP: Green Fluorescent Protein; DAPI: 4'-6-diamidino-2-phenylindole; ChIP: Chromatin immunoprecipitation; RNR: Ribonucleotide reductase; SDS-PAGE: Sodium Dodecyl Sulfate-Polyacrylamide Gel Electrophoresis.

\section{Competing interests}

The authors declare that they have no competing interests.

\section{Authors' contributions}

SDU carried out the viability tests, bulk chromatin fractionation, all western blotting experiments and some of the microscopy experiments. ASZ participated in the construction of yeast strains, some of the microscopy experiments and carried out the in situ chromatin binding assays. AMl constructed some of the yeast strains. SSS participated in the design of the study. MNN-V designed the experiments, drafted the manuscript and guided all of the experiments. All authors read and approved the final manuscript.

\section{Authors' information}

ASZ and AMI were Master degree diploma students, supervised by MNN-V, SDU is a PhD student, supervised by MNN-V, SSS is a collaborator of the group.

\section{Acknowledgements}

This work was supported by the National Science Fund of the Bulgarian Ministry of Education and Science MY-5-1507/05 and ДOO2 291/18.12.2008 (MU01/0137) and ДO3-198/10.04.2014 - "Science and Business", financed by the Operational Programme "Human Resources Development" at the European Social Fund. We would like to thank Dr. Sue Jaspersen for kindly providing us the yeast strain SL3517 (HTB2-mCherry). We are also thankful to Dr. Anastas Gospodinov and Miroslav Velev for critical reading of the manuscript.

Received: 16 July 2014 Accepted: 17 October 2014 Published: 31 October 2014

\section{References}

1. Bando M, Katou Y, Komata M, Tanaka H, Itoh T, Sutani T, Shirahige K: Csm3, Tof1, and Mrc1 form a heterotrimeric mediator complex that associates with DNA replication forks. J Biol Chem 2009, 284:34355-34365.
2. Alcasabas AA, Osborn AJ, Bachant J, Hu F, Werler PJ, Bousset K, Furuya K, Diffley JF, Carr AM, Elledge SJ: Mrc1 transduces signals of DNA replication stress to activate Rad53. Nat Cell Biol 2001, 3:958-965.

3. Foss EJ: Tof1p regulates DNA damage responses during $S$ phase in Saccharomyces cerevisiae. Genetics 2001, 157:567-577.

4. Mayer ML, Pot I, Chang M, Xu H, Aneliunas V, Kwok T, Newitt R, Aebersold R, Boone C, Brown GW, Hieter P: Identification of protein complexes required for efficient sister chromatid cohesion. Mol Biol Cell 2004, 15:1736-1745.

5. Noguchi E, Noguchi C, McDonald WH, Yates JR III, Russell P: Swi1 and Swi3 are components of a replication fork protection complex in fission yeast. Mol Cell Biol 2004, 24:8342-8355.

6. Calzada A, Hodgson B, Kanemaki M, Bueno A, Labib K: Molecular anatomy and regulation of a stable replisome at a paused eukaryotic DNA replication fork. Genes Dev 2005, 19:1905-1919.

7. Nedelcheva MN, Roguev A, Dolapchiev LB, Shevchenko A, Taskov HB, Francis Stewart A, Stoynov SS: Uncoupling of unwinding from DNA synthesis implies regulation of MCM Helicase by Tof1/Mrc1/Csm3 checkpoint complex. J Mol Biol 2005, 347:509-521.

8. Shimaoka Y, Tajima S, Fujimori F, Yamabayashi C, Moriyama H, Terada M, Takada T, Suzuki E, Bando M, Sugiyama Y, Narita I: Effects of IS-741, a synthetic anti-inflammatory agent, on bleomycin-induced lung injury in mice. Lung 2009, 187:331-339.

9. Komata M, Bando M, Araki H, Shirahige K: The direct binding of Mrc1, a checkpoint mediator, to Mcm6, a replication helicase, is essential for the replication checkpoint against methyl methanesulfonate-induced stress. Mol Cell Biol 2009, 29:5008-5019.

10. Pursell ZF, Isoz I, Lundstrom EB, Johansson E, Kunkel TA: Yeast DNA polymerase epsilon participates in leading-strand DNA replication. Science 2007, 317:127-130.

11. Lou H, Komata M, Katou Y, Guan Z, Reis CC, Budd M, Shirahige K, Campbel $J$ : Mrc1 and DNA polymerase epsilon function together in linking DNA replication and the S phase checkpoint. Mol Cell 2008, 32:106-117.

12. Bjergbaek L, Cobb JA, Tsai-Pflugfelder M, Gasser SM: Mechanistically distinct roles for Sgs1p in checkpoint activation and replication fork maintenance. Embo J 2005, 24:405-417.

13. Ho Y, Gruhler A, Heilbut A, Bader GD, Moore L, Adams SL, Millar A, Taylor P, Bennett K, Boutilier K, Yang L, Wolting C, Donaldson I, Schandorff S, Shewnarane J, Vo M, Taggart J, Goudreault M, Muskat B, Alfarano C, Dewar D, Lin Z, Michalickova K, Willems AR, Sassi H, Nielsen PA, Rasmussen KJ, Andersen JR, Johansen LE, Hansen LH, et al: Systematic identification of protein complexes in Saccharomyces cerevisiae by mass spectrometry. Nature 2002, 415:180-183.

14. Warren CD, Eckley DM, Lee MS, Hanna JS, Hughes A, Peyser B, Jie C, Irizarry R, Spencer FA: S-phase checkpoint genes safeguard high-fidelity sister chromatid cohesion. Mol Biol Cell 2004, 15:1724-1735.

15. Pan X, Ye P, Yuan DS, Wang X, Bader JS, Boeke JD: A DNA integrity network in the yeast Saccharomyces cerevisiae. Cell 2006, 124:1069-1081.

16. Collins SR, Miller KM, Maas NL, Roguev A, Fillingham J, Chu CS, Schuldiner M, Gebbia M, Recht J, Shales M, Ding H, Xu H, Han J, Ingvarsdottir K, Cheng B, Andrews B, Boone C, Berger SL, Hieter P, Zhang Z, Brown GW, Ingles CJ, Emili A, Allis CD, Toczyski DP, Weissman JS, Greenblatt JF, Krogan NJ: Functional dissection of protein complexes involved in yeast chromosome biology using a genetic interaction map. Nature 2007, 446:806-810.

17. Bermudez VP, Farina A, Tappin I, Hurwitz J: Influence of the human cohesion establishment factor Ctf4/AND-1 on DNA replication. J Biol Chem 2010, 285:9493-9505.

18. Hanna JS, Kroll ES, Lundblad V, Spencer FA: Saccharomyces cerevisiae CTF18 and CTF4 are required for sister chromatid cohesion. Mol Cell Biol 2001, 21:3144-3158.

19. Williams DR, Mclntosh JR: Mcl1p is a polymerase alpha replication accessory factor important for S-phase DNA damage survival. Eukaryot Cell 2005, 4:166-177.

20. Gambus A, van Deursen F, Polychronopoulos D, Foltman M, Jones RC, Edmondson RD, Calzada A, Labib K: A key role for Ctf4 in coupling the MCM2-7 helicase to DNA polymerase alpha within the eukaryotic replisome. Embo J 2009, 28:2992-3004.

21. Zhou Y, Wang TS: A coordinated temporal interplay of nucleosome reorganization factor, sister chromatin cohesion factor, and DNA polymerase alpha facilitates DNA replication. Mol Cell Biol 2004, 24:9568-9579. 
22. Williams DR, McIntosh JR: $m c l 1+$, the Schizosaccharomyces pombe homologue of CTF4, is important for chromosome replication, cohesion, and segregation. Eukaryot Cell 2002, 1:758-773.

23. Tsutsui $Y$, Morishita T, Natsume T, Yamashita K, Iwasaki H, Yamao F, Shinagawa $H$ : Genetic and physical interactions between Schizosaccharomyces pombe Mcl1 and Rad2, Dna2 and DNA polymerase alpha: evidence for a multifunctional role of Mcl1 in DNA replication and repair. Curr Genet 2005, 48:34-43.

24. Zhu W, Ukomadu C, Jha S, Senga T, Dhar SK, Wohlschlegel JA, Nutt LK, Kornbluth S, Dutta A: Mcm10 and And-1/CTF4 recruit DNA polymerase alpha to chromatin for initiation of DNA replication. Genes Dev 2007 21:2288-2299.

25. Tanaka H, Katou Y, Yagura M, Saitoh K, Itoh T, Araki H, Bando M, Shirahige K: $\mathrm{Ctf} 4$ coordinates the progression of helicase and DNA polymerase alpha. Genes Cells 2009, 14:807-820.

26. Errico A, Cosentino C, Rivera T, Losada A, Schwob E, Hunt T, Costanzo V: Tipin/Tim1/And1 protein complex promotes Pol alpha chromatin binding and sister chromatid cohesion. Embo J 2009, 28:3681-3692.

27. Morohashi H, Maculins T, Labib K: The amino-terminal TPR domain of Dia2 tethers SCF(Dia2) to the replisome progression complex. Curr Bio/ 2009, 19:1943-1949.

28. Koepp DM, Kile AC, Swaminathan S, Rodriguez-Rivera V: The F-box protein Dia2 regulates DNA replication. Mol Biol Cell 2006, 17:1540-1548.

29. Mimura S, Komata M, Kishi T, Shirahige K, Kamura T: SCF(Dia2) regulates DNA replication forks during S-phase in budding yeast. Embo J 2009, 28:3693-3705

30. Melo JA, Cohen J, Toczyski DP: Two checkpoint complexes are independently recruited to sites of DNA damage in vivo. Genes Dev 2001, 15:2809-2821.

31. Paulovich $A G$, Hartwell $\mathrm{LH}$ : A checkpoint regulates the rate of progression through S phase in S. cerevisiae in response to DNA damage. Cell 1995, 82:841-847.

32. Kiser GL, Weinert TA: Distinct roles of yeast MEC and RAD checkpoint genes in transcriptional induction after DNA damage and implications for function. Mol Biol Cell 1996, 7:703-718.

33. Osborn AJ, Elledge SJ: Mrc1 is a replication fork component whose phosphorylation in response to DNA replication stress activates Rad53. Genes Dev 2003, 17:1755-1767.

34. Tomonaga T, Nagao K, Kawasaki Y, Furuya K, Murakami A, Morishita J, Yuasa T, Sutani T, Kearsey SE, Uhlmann F, Nasmyth K, Yanagida M: Characterization of fission yeast cohesin: essential anaphase proteolysis of Rad21 phosphorylated in the S phase. Genes Dev 2000, 14:2757-2770.

35. Grallert B, Kearsey SE, Lenhard M, Carlson CR, Nurse P, Boye E, Labib K: A fission yeast general translation factor reveals links between protein synthesis and cell cycle controls. J Cell Sci 2000, 113(Pt 8):1447-1458.

36. Todorov IT, Attaran A, Kearsey SE: BM28, a human member of the MCM2-3-5 family, is displaced from chromatin during DNA replication. J Cell Biol 1995, 129:1433-1445.

37. Kearsey SE, Montgomery S, Labib K, Lindner K: Chromatin binding of the fission yeast replication factor $\mathrm{mcm} 4$ occurs during anaphase and requires ORC and cdc18. Embo J 2000, 19:1681-1690.

38. Amano $Y$, Enomoto $M$, Bando $M$, Kawakami M, Sugiyama $Y$ : Hypersensitity pneumonitis in a greenhouse rose grower. Nihon Kokyuki Gakkai Zasshi 2009 , 47:960-964.

39. Tourriere H, Versini G, Cordon-Preciado V, Alabert C, Pasero P: Mrc1 and Tof1 promote replication fork progression and recovery independently of Rad53. Mol Cell 2005, 19:699-706.

40. Petermann E, Helleday T, Caldecott KW: Claspin promotes normal replication fork rates in human cells. Mol Biol Cell 2008, 19:2373-2378.

41. Hodgson B, Calzada A, Labib K: Mrc1 and Tof1 regulate DNA replication forks in different ways during normal S phase. Mol Biol Cell 2007, 18:3894-3902

42. Voineagu I, Narayanan V, Lobachev KS, Mirkin SM: Replication stalling at unstable inverted repeats: interplay between DNA hairpins and fork stabilizing proteins. Proc Natl Acad Sci U S A 2008, 105:9936-9941.

43. Cokol M, Nair R, Rost B: Finding nuclear localization signals. EMBO Rep 2000, 1:411-415.

44. Huh WK, Falvo JV, Gerke LC, Carroll AS, Howson RW, Weissman JS, O'Shea EK: Global analysis of protein localization in budding yeast. Nature 2003, 425:686-691.
45. Tonami Y, Murakami H, Shirahige K, Nakanishi M: A checkpoint control linking meiotic $S$ phase and recombination initiation in fission yeast. Proc Natl Acad Sci U S A 2005, 102:5797-5801.

46. Fong CM, Arumugam A, Koepp DM: The Saccharomyces cerevisiae F-box protein Dia2 is a mediator of S-phase checkpoint recovery from DNA damage. Genetics 2013, 193:483-499.

47. Calvert ME, Lannigan J: Yeast cell cycle analysis: combining DNA staining with cell and nuclear morphology. Curr Protoc Cytom 2010, Chapter 9. Unit 932 31-16.

48. Shimmoto M, Matsumoto S, Odagiri $Y$, Noguchi E, Russell P, Masai $H$ : Interactions between Swi1-Swi3, Mrc1 and S phase kinase, Hsk1 may regulate cellular responses to stalled replication forks in fission yeast. Genes Cells 2009, 14:669-682.

49. Yoshizawa-Sugata N, Masai H: Human Tim/Timeless-interacting protein, Tipin, is required for efficient progression of $\mathrm{S}$ phase and DNA replication checkpoint. J Biol Chem 2007, 282:2729-2740.

50. Tanaka H, Kubota Y, Tsujimura T, Kumano M, Masai H, Takisawa H: Replisome progression complex links DNA replication to sister chromatid cohesion in Xenopus egg extracts. Genes Cells 2009, 14:949-963.

51. Vidanes GM, Sweeney FD, Galicia S, Cheung S, Doyle JP, Durocher D, Toczyski DP: $C D C 5$ inhibits the hyperphosphorylation of the checkpoint kinase Rad53, leading to checkpoint adaptation. PLOS Biol 2010, 8:e1000286.

52. Pellicioli A, Lee SE, Lucca C, Foiani M, Haber JE: Regulation of Saccharomyces Rad53 checkpoint kinase during adaptation from DNA damage-induced G2/M arrest. Mol Cell 2001, 7:293-300.

53. Yoo HY, Kumagai A, Shevchenko A, Dunphy WG: Adaptation of a DNA replication checkpoint response depends upon inactivation of Claspin by the Polo-like kinase. Cell 2004, 117:575-588.

54. Chabes A, Georgieva B, Domkin V, Zhao X, Rothstein R, Thelander L: Survival of DNA damage in yeast directly depends on increased dNTP levels allowed by relaxed feedback inhibition of ribonucleotide reductase. Cell 2003, 112:391-401.

55. Zhao X, Rothstein R: The Dun 1 checkpoint kinase phosphorylates and regulates the ribonucleotide reductase inhibitor Sml1. Proc Natl Acad Sci U S A 2002, 99:3746-3751.

56. Branzei D, Foiani M: The checkpoint response to replication stress. DNA Repair (Amst) 2009, 8:1038-1046.

57. Zhao X, Chabes A, Domkin V, Thelander L, Rothstein R: The ribonucleotide reductase inhibitor $\mathrm{Sml} 1$ is a new target of the Mec1/Rad53 kinase cascade during growth and in response to DNA damage. Embo J 2001, 20:3544-3553.

58. Zhou Z, Elledge SJ: DUN1 encodes a protein kinase that controls the DNA damage response in yeast. Cell 1993, 75:1119-1127.

59. Alvino GM, Collingwood D, Murphy JM, Delrow J, Brewer BJ, Raghuraman MK: Replication in hydroxyurea: it's a matter of time. Mol Cell Biol 2007, 27:6396-6406

60. Gietz RD, Jean AS, Woods RA, Schiestl RH: Improved method for high efficiency transformation of intact yeast cells. NAR 1992, 20:1425.

61. Akada R, Murakane T, Nishizawa Y: DNA extraction method for screening yeast clones by PCR. Biotechniques 2000, 28:668-670. 672, 674.

62. Silva S, Gallina I, Eckert-Boulet N, Lisby M: Live cell microscopy of DNA damage response in Saccharomyces cerevisiae. Methods Mol Biol 2012, 920:433-443.

63. Liang C, Stillman B: Persistent initiation of DNA replication and chromatin-bound MCM proteins during the cell cycle in cdc6 mutants. Genes Dev 1997, 11:3375-3386.

64. Foiani M, Marini F, Gamba D, Lucchini G, Plevani P: The B subunit of the DNA polymerase alpha-primase complex in Saccharomyces cerevisiae executes an essential function at the initial stage of DNA replication. Mol Cell Biol 1994, 14:923-933.

doi:10.1186/1747-1028-9-4

Cite this article as: Uzunova et al:: The subunits of the S-phase checkpoint complex Mrc1/Tof1/Csm3: dynamics and interdependence. Cell Division 2014 9:4. 